\title{
Gênero e emoções na publicidade da imprensa feminina
}

\author{
CHARLES ANTONIO PEREIRA
}

Universidade Federal de Juiz de Fora, Juiz de Fora, Minas Gerais, Brasil

DOI 10.11606/issn.2316-9133.v28i2p260-281

resumo Com base na análise das peças publicitárias de produtos cosméticos presentes em exemplares da década de 1920 da revista A Cigarra e do ano de 2016 da revista Marie Claire, buscarei demonstrar as permanências e descontinuidades nos discursos regulatórios de gênero a respeito dos estilos de feminilidades veiculados por essas publicações. Procuro discutir como, apesar das inúmeras conquistas femininas no decorrer desses quase cem anos que as distanciam, muito do discurso publicitário da década de 1920 se apresenta de maneira semelhante às publicações voltadas para as mulheres na atualidade, por vezes se reinventando em relação à forma, mas se mantendo fiel a um conteúdo historicamente implícito sobre o papel feminino hegemônico em nossa sociedade. Aliado a isso, procuro analisar ainda como o discurso publicitário se apropria de uma "linguagem das emoções” baseada nos papéis tradicionais de gênero a fim de se aproximar de seu públicoalvo.

palavras-chave Gênero; feminilidades; imprensa feminina; emoções; revistas

\section{Gender and emotion in women's press advertisings}

abstract Based on the analysis of the advertising of cosmetic products present in the 1920s copies of A Cigarra magazine and 2016s copies Marie Claire magazine, I will try to demonstrate the permanence and discontinuities in the regulatory discourses regarding the femininity linked by these publications. Thus demonstrating that, despite the innumerable female achievements over the nearly one hundred years that distance them, much of the advertising discourse of the 1920s is presented in a similar way in publications aimed at women today, sometimes reinventing themselves in relation to form, but sticking to a historically implicit content about the hegemonic female role in our society. In addition, I also try to analyse how advertising discourse appropriates a "language of emotions" based on traditional gender roles, in order to get closer to its target audience.

keywords Gender; femininities; women's press; emotions; magazines 


\section{Introdução}

Este trabalho é resultado dos desdobramentos da minha pesquisa de mestrado, cujo objetivo foi analisar comparativamente a construção dos discursos a respeito do corpo e estilos de feminilidades na publicidade de produtos cosméticos presentes na imprensa feminina em publicações de períodos históricos distintos (PEREIRA, 2017). Foco aqui no papel central das emoções na produção das peças publicitárias examinando a hipótese de que essa centralidade teria o intuito de proporcionar uma aproximação com a leitora. Uma vez que, seguindo a lógica da "etnopsicologia ocidental" (Lutz, 1988), uma maior sensibilidade às emoções tende a ser associada ao âmbito feminino. Tal como as emoções tendem a ser associadas aos hormônios, essa percepção efetuada pela impressa feminina é utilizada a fim de endereçar sua publicidade às "mulheres", seu público-alvo, associando-as aos padrões hegemônicos de feminilidades como, por exemplo, ao discurso de que mulheres se interessam mais por temas relacionados ao amor e questões sentimentais, etc.

Apesar da extensa produção científica, nas mais diversas áreas que tomam a imprensa feminina como objeto privilegiado de pesquisa (BUITONI, 1986; BERGER, 2006; SANT'ANNA, 2014), atualmente esse tipo de imprensa, mesmo em um contexto de diminuição da circulação de revistas impressas - seu meio clássico e privilegiado de circulação - ainda se configura como um objeto de pesquisa estimulante, devido a sua complexidade e implicações sociais, econômicas e culturais (Buitoni, 1986), além de seu caráter contínuo e processual que corrobora para que a temática continue oferecendo novas abordagens analíticas, e fatos que ainda não foram explorados em sua totalidade. Isto é, enquanto um processo histórico e cultural ainda em andamento, o esgotamento analítico a respeito da imprensa feminina se encontra em horizontes ainda não vislumbrados (SULLEROT, 1963, p. 06).

Dito isto, cabe ressaltar que as abordagens clássicas a respeito da imprensa feminina possuem alguns limites de análise, sendo o principal deles sua clara produção dentro do escopo teórico dos chamados "Estudos sobre Mulher". De acordo com Heilborn e Sorj (1999) os "Estudos sobre a Mulher", "Estudos de Gênero" ou de "Relações de Gênero", foram as fórmulas encontradas para a institucionalização do diálogo do feminismo com a academia brasileira. A escolha do uso conceitual de cada um dos termos não é ingênua e nem arbitrária, pois cada um deles remete aos limites dessas áreas de estudos. Nesse sentido, os "Estudos sobre a Mulher" surgiram na década de 1970, momento em que livros, seminários e artigos faziam constar em seus títulos o termo "mulher" e pretendiam principalmente preencher lacunas do conhecimento sobre a situação das mulheres nas mais variadas esferas da vida.

Com obras clássicas sobre a temática, os trabalhos de Buitoni $(1986$; 1999) são um exemplo claro desse tipo de produção, pois se sustentam a partir da produção de históricos detalhados compostos por exemplos retirados de revistas femininas e buscam demonstrar como eram elaborados os papéis tradicionais femininos em suas páginas no decorrer da evolução desse tipo de imprensa. Suas análises são meticulosas em relação à caracterização do fenômeno, porém pecam ao deixar de fora uma análise mais crítica em relação a como 
esse tipo de imprensa contribui para a manutenção das relações de poder e dominação entre os gêneros.

Portanto, apesar de utilizar estas abordagens tradicionais da imprensa feminina como fontes primárias para pensar sua temporalidade, buscarei me distanciar dessas perspectivas na medida em que busco priorizar uma abordagem comparativa do fenômeno, que priorize uma perspectiva de gênero para pensar suas hierarquias internas, e os usos das emoções pelo discurso publicitário presente nesses periódicos como tentativa de aproximação do seu público-alvo.

Dessa forma, concentrarei minhas análises em peças publicitárias emblemáticas selecionadas de duas publicações distintas da imprensa feminina e que são representativas de sua época. As publicações analisadas e comparadas serão: a revista A Cigarra, mais especificamente alguns números publicados na década de 1920; e Marie Claire, com números lançados em 2016. Através da comparação do material retirado dessas publicações, busco demonstrar possíveis permanências e continuidades no discurso acerca das feminilidades presentes na imprensa feminina.

Para o tratamento do material, foi realizada uma etnografia de documentos, onde analisei seis exemplares de A Cigarra do ano de 1925 - compreendendo o período de três meses, por se tratar de uma publicação quinzenal - e seis exemplares da Marie Claire, compreendendo o período de seis meses, por ser uma publicação mensal. A consulta dos exemplares de A Cigarra foi realizada a partir do acervo digitalizado do Arquivo Público do Estado de São Paulo disponibilizados online ${ }^{1}$. Já no caso da Marie Claire, por se tratar de uma revista ainda em circulação, pude analisar seus exemplares a partir da compra dos mesmos, destinados às bancas de revistas mensalmente. Cabe ressaltar que durante as análises empreendeu-se um movimento de pensar o texto publicitário juntamente ao contexto histórico e social da época de cada publicação, para dessa forma tentar da melhor forma a reconstrução dos cenários de circulação das revistas.

A partir da análise de conteúdo das revistas, foi produzido um arquivo pessoal, no qual cataloguei as peças publicitárias presentes nos exemplares, onde pude chegar a uma média de 80 peças publicitárias presentes em cada exemplar de A Cigarra, sendo que $70 \%$ delas vinculavam imagens femininas aos seus produtos, em sua maioria produtos cosméticos. $\mathrm{Na}$ Marie Claire pude constatar uma média de 50 peças publicitárias por revista, sendo que 80\% vinculavam imagens femininas, equilibradas entre produtos cosméticos e peças de vestuário (PEREIRA, 2017, p.17). Devido à impossibilidade de analisar aqui todo o conteúdo detalhadamente, priorizei na seleção do material, peças publicitárias que traziam em maior evidencia um alinhamento com estilos de feminilidades hegemônicos de cada período histórico.

Dito isto, é importante ressaltar que se torna possível analisar e comparar publicações de épocas distintas porque, sob certo plano de observação, as imagens

1 http://www.arquivoestado.sp.gov.br/site/acervo/repositorio_digital/jornais_revistas 
publicitárias apontam para uma evolução de suas fórmulas, no sentindo de acompanhar as mudanças sociais; porém, se observadas de outro plano, vemos também uma impressionante recorrência entre os significados dessas imagens em momentos diversos. Em outras palavras, as representações e as imagens na imprensa feminina ao longo dos tempos "mudam sem mudar" (Rocha, 2006, p.40). Outro fato que proporciona esse critério de análise diz respeito à constatação da existência de temas tradicionais da imprensa feminina. De acordo com Buitoni (2009), os temas tradicionais da imprensa feminina resumem-se a "meia dúzia" de itens: moda, beleza, culinária, decoração, comportamento e celebridades $E$ tal constatação se confirmou durante as minhas pesquisas, visto que temas como moda, beleza e comportamento são recorrentes tanto em A Cigarra, quanto na Marie Claire.

$\mathrm{O}$ artigo se divide em cinco partes. A primeira é dedicada à discussão do processo de surgimento e consolidação da imprensa feminina. A segunda se dedica à contextualização e à apresentação das peças publicitárias selecionadas da imprensa feminina da década de 1920. A terceira parte se dedica às peças publicitárias atuais da revista Marie Claire. A quarta parte visa discutir o uso das emoções no discurso publicitário da imprensa feminina, seguido das considerações finais que trazem uma comparação das duas publicações analisadas neste trabalho.

\section{Tempos e histórias da imprensa feminina}

O que caracteriza uma publicação enquanto pertencente ao fenômeno da imprensa feminina são algumas de suas características singulares no que diz respeito a sua estruturação e temas de predileção extremamente recorrentes nas publicações do gênero. De imediato, vale ressaltar que "imprensa feminina" é uma categoria definitivamente generificada: o gênero de seu público-alvo faz parte de sua natureza, e desde que surgiu no século XVII tal nicho já trouxe a destinação "às mulheres" em seu título. Buitoni (2009) afirma que, entre a literatura e as chamadas artes domésticas, o jornalismo feminino já nasceu complementar, revestido de um caráter secundário, tendo como função o entretenimento e, no máximo, um utilitarismo prático ou didático. Ou seja, em seu surgimento, a imprensa feminina não trazia nenhum caráter emancipatório para a condição social das mulheres e nenhum caráter político: pelo contrário, reforçava papéis tradicionais de gênero e idealizava o feminino a partir de um âmbito de domesticidade (PEREIRA,2017, p.22).

A imprensa feminina possui seu berço na Europa e seu primeiro exemplar impresso destinado especificamente às mulheres tem seu primeiro número lançado no final do século XVII. Conhecido como Lady's Mercury, lançado em 1693 na Inglaterra, foi o primeiro periódico destinado às mulheres de que se tem notícias. Posteriormente, por volta da segunda metade do século XVIII, esse tipo de imprensa passou por um processo de difusão pelo continente europeu, tornando-se populares publicações como o Courrier de La Donne em 1758, Toillette na Itália em 1770, e Alemanha Akademie Der Grazien em 1774, que possuíam um formato mais semelhante com o atual (PEREIRA, 2017, p.21). 
O principal país expoente nesse tipo de imprensa foi a França. Seu modelo foi seguido por diversos outros, inclusive no Brasil, onde o surgimento da imprensa feminina data do século XIX. Almeida (2002) - refletindo a partir das telenovelas e do consumo feminino - aponta para um caminho parecido quando trata dessa relação de inspiração do modelo francês pela imprensa no Brasil e a associação do feminino com certas produções culturais.

A associação entre mulheres e telenovelas seria um desdobramento de associações mais antigas entre o feminino e certas produções culturais. As histórias seriadas dos folhetins, melodramas em capítulos editados nos pés de página dos jornais, teriam sido responsáveis pela ampliação da circulação do material impresso. Os jornais alargaram muito suas vendas ao incluir em sua produção a expectativa de que as mulheres também poderiam ser leitoras - e assim os folhetins foram parte de uma estratégia de atração das leitoras do sexo feminino (assim como a inclusão de cadernos femininos com receitas para a vida doméstica). $O$ folhetim nasceu na França no século XIX, mas o modelo de produção cultural de narrativas melodramáticas em fascículos se expandiu por muitos países do mundo ocidental, inclusive o Brasil, ainda no mesmo século (ALMEIDA, 2002, p. 173).

Para reforçar o caráter secundário da imprensa feminina, basta nos atentarmos ao fato de que no passado nunca se ouvira falar de uma "imprensa masculina", pois não havia uma segmentação dos leitores em relação aos gêneros. Havia somente "imprensa", que apesar de não ter uma evidente destinação, subentende-se que era direcionada aos homens, vide suas temáticas. Tal direcionamento possuía também um caráter prático: a educação das mulheres não era incentivada e, dessa forma, a grande maioria não teria acesso ao conteúdo por não serem letradas (PEREIRA, 2017, p.22). Portanto, a imprensa feminina deriva da imprensa em geral, a partir da segmentação de temas entendidos como femininos, como etiqueta, boas maneiras, assuntos ligados ao sentimento e o coração etc.

No Brasil, a imprensa feminina se consolidou tardiamente, visto que até o século XVIII não havia imprensa de nenhuma espécie. O primeiro periódico feminino de que se tem notícia é o carioca $O$ Espelho Diamantino, lançado em 1827. Suas páginas tratavam de assuntos como literatura, belas artes e moda. Essa publicação trazia um importante atributo em seu corpo editorial: "Dedicado às senhoras brasileiras" (FONSECA apud BUITONI, 1986). Posteriormente, outras publicações seguiram o exemplo e assumiram tais moldes apresentados pelo Espelho Diamantino, como o claro direcionamento às mulheres. Dentre essas publicações: no Recife, o Espelho das Brasileiras, Jornal das variedades em 1835, Relator de Novellas em 1838 e Espelho das Bellas em 1841; no Rio de Janeiro surgiram Correio das Modas (1839 - 1841) e A Marmota, que foi um jornal literário responsável pelas primeiras 
litogravuras brasileiras. Uma questão interessante para se observar a respeito da grande maioria das publicações do período direcionadas para as mulheres são as peculiaridades dos seus nomes, quase sempre fazendo conotação a algo associado ao dia-a-dia delas. A destinação ao público feminino já era observável a partir das capas.

Seus nomes já caracterizavam sua destinação (o uso de flores, pedras, ou a menção a mulher no título). A denominação "espelho", bastante empregada deve ter vindo da França, onde existiam alguns jornais com o mesmo substantivo: por exemplo, Le Miroir des Dames (na década de 1830). Assim a continuação do Correio das Modas cariocas chamou-se $O$ Espelho Fluminense (1843) - com modas, literatura e charadas - publicado por E.e H. Laemmert. E, em 1859, foi lançado O Espelho, revista de literatura, modas, indústria e artes, tendo Machado de Assis como colaborador desde o primeiro número (BUITONI, 2009, p. 33).

Igualmente ao que se verificou na Europa e nos Estados Unidos, o analfabetismo no Brasil se configurava como uma das principais barreiras para a disseminação da imprensa, principalmente no que diz respeito à mulher, devido ao seu baixo índice de alfabetização. Segundo Maria Celeste Mira:

A leitura só fazia parte dos hábitos de uma pequena elite culta e rica cujos filhos eram educados por perceptores e concluíam seus estudos na Europa. Até meados do século, frequentar as poucas escolas da corte só era permitido aos homens. Para as mulheres que raramente saíam de casa a não ser para ir à missa, e tinham como únicas ocupações a confecção de renda, o preparo de doces e os mexericos com as escravas da casa, o analfabetismo era signo de nobreza e de virtude, pois afastava os perigos dos amores secretos por correspondência. Um reduzido público leitor feminino começa a se formar, na segunda metade do século, quando se torna normal para as jovens brasileiras bem-nascidas frequentar, nas maiores cidades, uma escola elegante. $E$ isso foi o suficiente para influir no mercado de revistas. Dependendo do conteúdo, as revistas eram consideradas com conteúdos apropriadas para as mulheres. (MIRA, 2008, p.26).

Apesar de todas as dificuldades enfrentadas para a popularização da imprensa, foi por volta do ano de 1840 que um dos seus primeiros modelos editoriais começou a conquistar certa visibilidade. $\mathrm{O}$ folhetim se tornou o modelo de publicação mais popular no Brasil. Inicialmente esse era o nome dado aos rodapés das páginas dos jornais que passavam algum tipo de informação utilitária, como pequenas notas sociais, resenhas literárias, etc. Devido 
ao sucesso desse tipo de publicação, posteriormente o folhetim acabou transformando-se em publicações independentes. (BUITONI, 2009, p.30))

Em relação ao posicionamento da imprensa feminina no final do século XIX e início do século XX, aponta-se duas posturas: a primeira delas, mais arraigada ao tradicionalismo, que não permite a ação da mulher fora do lar e engrandece as virtudes domésticas e as qualidades ditas "femininas"; a segunda, mais "progressista", que se posiciona a favor dos direitos das mulheres, principalmente dando grande ênfase à educação (Buitoni, 2009). Todavia, mesmo na postura dita "progressista", pode-se perceber a existência de um discurso que ainda se apresentava atrelado a valores domésticos, mesmo que de forma menos enfática. Porém, deve-se reconhecer que tal fato já demonstrava um avanço, devido à educação feminina ser priorizada em alguma medida, mesmo que com o intuito de educar a família. Transcrevo abaixo o exemplo utilizado por Buitoni (2009) para ilustrar o discurso progressista:

O Brasil atravessa neste momento uma das phases mais importantes do seu desenvolvimento, isto é, a generosa propaganda em favor da mulher. Porém a base principal do verdadeiro progresso é a educação e só se poderá realizar esse gigantesco passo de tão sublime evolução, com a educação das mulheres. [...] E indispensável educa-la: sem instrução ela continuará a representar o tristíssimo papel que na maioria tem feito, como esposa principalmente e nos outros estados da vida. [...] E não é só isso! : - A mulher que rodeada de sua família, se instrui para instruir, que engrandece sua alma para exercer toda a sua influência pela prática das virtudes torna- se digna do respeito dos homens, e será nesse culto sempre moça e bela. (BUITONI, 2009, p. 49)

Com a chegada do século XX, os populares folhetins - que eram publicações mais simples, de poucas páginas e com tiragens menores - dariam espaço às revistas ilustradas, como A Cigarra.

\section{A imprensa feminina na década de 1920}

Analisando a bibliografia sobre a imprensa, percebe-se que diversos autores apontam o início do século XX, período em que surge A Cigarra, como um momento de crescentes transformações no campo. Nelson Werneck Sodré (1986) já havia assinalado a diversificação e modernização técnica da imprensa nesse período:

A luta pela rapidez exigiu da imprensa sucessivos inventos, conduzindo à velocidade da impressão, acompanhando o enorme e crescente fluxo de informações, devido ao telégrafo, ao cabo submarino e, depois, ao telefone e ao rádio (SODRÉ, 1986, p. 94). 
Nas primeiras décadas do século $\mathrm{XX}$, a grande diversidade de jornais e revistas publicados em circulação na cidade de São Paulo surgiu como uma referência importante sobre a vida cultural de diferentes grupos sociais, principalmente os mais abastados economicamente (SODRÉ, 1986; MIRA, 2008).

Publicada entre 1914 e 1975, A Cigarra foi um periódico diretamente relacionado com as diversas transformações culturais ocorridas nas primeiras décadas do século XX, fazendo crer que a imprensa aparecia como uma consequência da "modernidade" que ocorria na época na cidade de São Paulo. Como um reflexo desse ideal de modernidade, pode-se apontar as mudanças drásticas no padrão estético feminino retratado por essas publicações. A década de vinte é marcada por uma desconstrução de uma silhueta feminina clássica. $O$ corpo se libertou das amarras dos espartilhos, encurtou-se o comprimento dos cabelos e deixou-se à mostra partes do corpo antes cobertas (SANT'ANNA, 2014, p. 39). Segundo Bonadio (2007), ao longo da década de 1920 as formas das roupas mudaram: as saias encurtaram, os espartilhos foram trocados por cintas elásticas, os vestidos ficaram mais simples, retos e soltos no corpo. As vestimentas em geral propiciavam maior conforto e liberdade de movimentos, o que facilitava a circulação das mulheres em espaços públicos, o que era prejudicado anteriormente pelo comprimento e amplitude dos vestidos. A imprensa feminina do período, a partir da assimilação de um ideal de modernidade muito popular nos centros urbanos da época, desempenhou função ativa na circulação desses novos modelos estéticos, sobretudo nas colunas sociais e nos anúncios de cosméticos e produtos de beleza (PEREIRA, 2017, p.30).

Um dos anúncios de produtos de beleza que podiam ser encontrados nessas publicações é o da Pasta Russa do Dr. G. Ricabal, que prometia o aumento progressivo dos seios no período de duas semanas. A peculiaridade de tal anúncio foi responsável por suscitar o meu interesse de pesquisa pela temática da imprensa feminina.

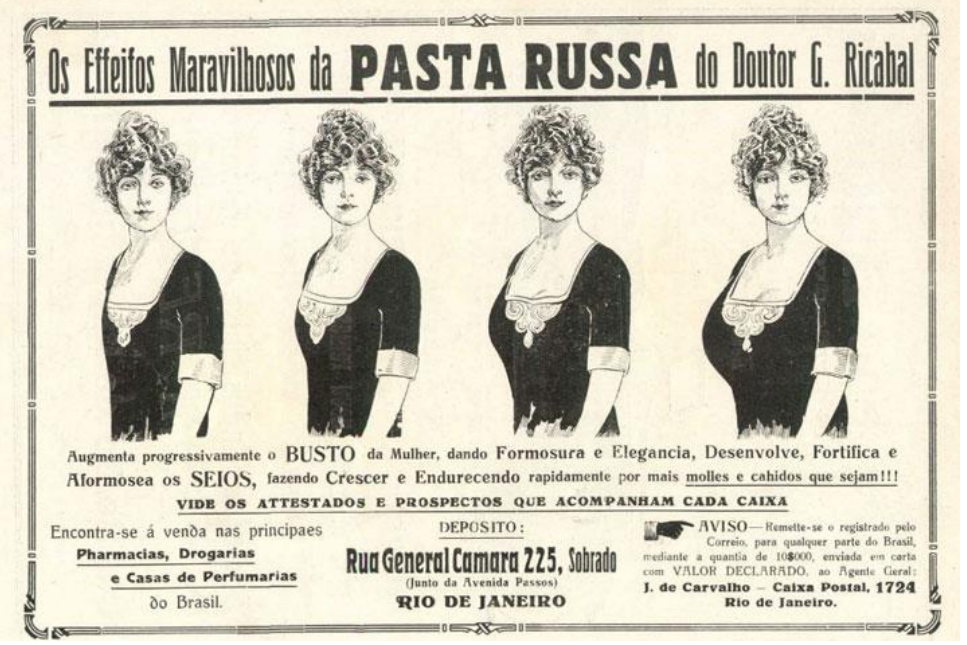

Figura 1. Pasta Russa do Dr. G. Ricabal. Fonte: A Cigarra, vol.1, número 244. 
Além de um discurso de embelezamento do corpo através da modificação de atributos físicos externos - como seios, cabelos, etc - produzia-se ainda discursos a respeito do funcionamento interno desse corpo. Falava-se de organismos obstruídos, lentos, constipados. Os pulmões, fígados e os rins figuravam como os principais órgãos que deveriam ser tratados para não apresentarem um mau funcionamento, o que causaria a famigerada "feiura". E para evitar tal consequência, uma infinidade de elixires, tônicos e remédios era amplamente vinculada nas páginas da imprensa feminina. Como é o caso das pílulas apresentadas abaixo.

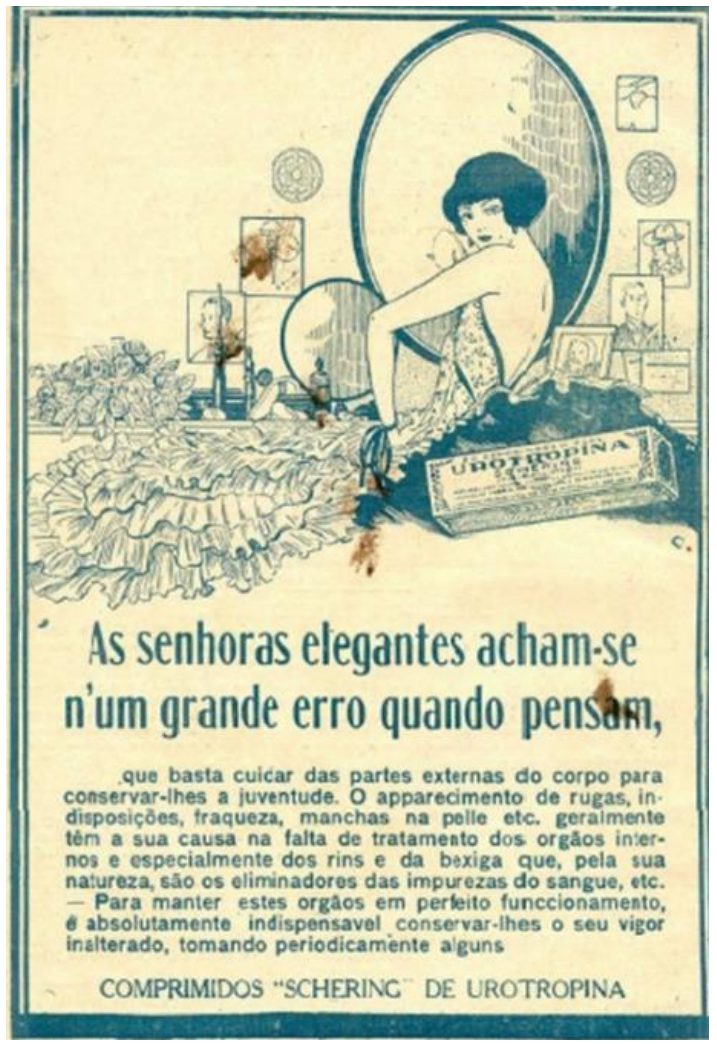

Figura 2. Comprimidos Schering. Fonte: A Cigarra, vol.1. Número 244.

O anúncio publicitário dos Comprimidos Schering de Urotropina demonstra bem essa preocupação com o bom funcionamento interno do organismo. Isso se evidencia através do texto que compõe o anúncio, na medida em que afirma:

As mulheres elegantes acham-se n'um grande erro quando pensam, que basta cuidar das partes externas do corpo para conserva-lhes a juventude. $\mathrm{O}$ apparecimento de rugas, indisposições, fraqueza, manchas na pelle, etc. geralmente têm sua causa na falta de tratamento dos órgãos internos, principalmente dos rins e da bexiga que, pela sua natureza, são eliminadores das impurezas do sangue, etc - Para manter estes órgãos em perfeito funccionamento, é absolutamente indispensável, conservar-lhes 
o seu vigor inalterado, tomando periodicamente alguns comprimidos (A Cigarra, vol.1. Número 244, 1925)

Dessa forma, torna-se explicita uma associação entre organismos "limpos" com o ideal hegemônico de beleza. O grande número de anúncios encontrados com produtos para essa finalidade durante minha análise das revistas permite demonstrar que os organismos eram entendidos naturalmente como "obstruídos", suscitando ainda mais a ideia de que os produtos agiriam como maneira de melhorar aquilo tido como atributo natural das funções corporais.

Nesse sentido, corpo saudável, "desobstruído", usando a categoria nativa, são naturalmente corpos belos. Cabe ressaltar que os corpos expostos são majoritariamente femininos, pois durante minhas análises não encontrei em nenhum dos números das revistas analisadas produtos que prometessem os mesmos efeitos, que fossem voltados para o público masculino ou usassem imagens masculinas como chamariz.

O discurso acerca dos "corpos obstruídos" coadunava com o propósito higienista do período. A partir de 1920 no Brasil, as autoridades governistas começam a emitir um discurso centrado na preocupação com a higiene da família, do ambiente em que ela vive, trabalha e circula, fundando um discurso organizador que visava criar normas gerais para a população (OLIVEIRA, 2003, p.76). O discurso higienista ou sanitarista também trazia normativas para o corpo feminino, uma vez que o cuidado com a família era da sua alçada (PEREIRA, 2017), deslocando assim, para o âmbito da doença, corpos que não se encaixavam nos padrões vigentes. O hábito de fortificar o corpo e limpá-lo de supostas impurezas foi uma das tendências alavancadas na época. E a propaganda, nesse sentido, adquire um valor inovador, principalmente no que se refere à propaganda de pastilhas, xaropes, licores e águas medicinais. A mensagem passada era clara: o estômago devia ser "liberado" de toda a "sujeira", o sangue precisava circular com facilidade e os pulmões necessitavam aperfeiçoar o seu trabalho respiratório.

Mas não se tratava apenas de curar ou limpar, nem de forçar o organismo a voltar às suas atividades naturais. O que se pretendia desde então era a ideia de "melhorar modificando", uma vez que o conjunto do corpo humano se revelou subitamente lento: não bastava contentar-se com a digestão natural, era preciso dinamizá-la com o consumo de remédios e atividades físicas (PEREIRA, 2017, p.56). Sugere-se um ideal produtivista, onde o corpo poderia ser "feito" a partir de cosméticos e atividades físicas. Nesse sentido, o aumento da medicalização do corpo obteve apoio de grande parte da propaganda.

\section{Imprensa feminina no contexto atual}

A revista Marie Claire foi criada no ano de 1937 pelo industrial francês Jean Prouvost e pela escritora Marcelle Auclair, com circulação semanal toda quarta-feira. O nome da nova publicação foi inspirado em Marie-Claire Mendès France, uma jornalista e ativista política que batalhou pelos direitos humanos e principalmente pelos direitos das mulheres. A Marie 
Claire também revolucionou ao longo dos tempos o conceito gráfico das revistas femininas, inspirando-se nas publicações ditas mais sofisticadas e investindo em uma diagramação inovadora, repleta de páginas com muito papel e pouco texto, branco em profusão e renovações tipográficas. Rapidamente a revista atraiu e conquistou muitos leitores, em sua grande maioria mulheres, atingindo um enorme sucesso em pouco tempo de mercado. Com o início da Segunda Guerra Mundial, em virtude da ocupação germânica no sul da França, muitas das revistas francesas foram suspensas e a Marie Claire não fugiu a essa regra ${ }^{2}$.

A revista só voltou a ser editada em 1954. No mercado brasileiro foi lançada em abril de 1991, pela editora Globo. No lançamento no país, Regina Lemos, diretora da revista na época, escreveu em sua primeira carta à leitora:

Desde 1954, quando surgiu em Paris, Marie Claire é ousada, pioneira, capaz de quebrar tabu como o de que uma revista feminina não pode tratar de assuntos ditos pesados, e que o espírito da reportagem atuante, polêmica e informativa não combina com matérias de moda, beleza e culinária. Marie Claire rompe com estes padrões dos quais estamos cansadas, e junta o que as outras separam assumindo (com êxito) a contradição de que existe na vida, entre belo e chocante, entre prazer e dor". (BUITONI, 2009, p.143)

No Brasil, a revista mensal é comandada, basicamente, por um corpo editorial feminino, e apresenta em torno de 150 páginas, número que varia de acordo com a edição. A década de 1990 foi marcada por grandes mudanças na revista, especialmente em seu formato, abordagem e editoração gráfica, passando a enfocar temas os mais diversos como artigos sobre relações e ascensão pessoais, beleza e boa forma, saúde e nutrição, causas sociais, estilo de vida (jardinagem, viagens, casa e esporte), entretenimento, carreira e tecnologia.

Com a análise da publicidade de cosméticos na imprensa feminina da década de 1920, foi possível verificar que a preocupação com a "melhoria" do corpo a partir de sua modificação era uma pauta recorrente e de muita importância. No contexto da imprensa feminina atual - e recorrendo ainda a um recuo no tempo, mais especificamente a partir dos anos 1960 em diante - aconteceram modificações importantes a respeito de como os cosméticos eram vinculados e como os seus resultados eram apresentados às consumidoras finais, já que buscavam demonstrar que os efeitos eram muito menos aparentes do que antes. A linguagem publicitária permanecia imperativa nos anos 1960: entretanto, diferentemente do que era visto anteriormente, sua linguagem convidava a mulher a ser "autêntica". No caso da maquiagem, por exemplo, Sant’anna (2014) afirma que, no lugar de um verniz, que

2 As informações aqui expostas foram levantadas a partir do site da própria publicação (https://www.marieclaire.com) e sites especializados em marketing editorial ( http://www.brandcha nnel.com; http://www.mundodomarketing.com.br) 
esconde as imperfeições por algumas horas, a maquiagem devia ser uma segunda pele. Logo, imperava uma ideia de que não se deveria distanciar a beleza dita natural de uma beleza construída. Dessa forma, "a beleza era interpretada como uma conquista individual, um trabalho que não tem hora para começar ou acabar" (SANT'ANNA, 2014, p.123).

Trazendo para o contexto de minhas análises, a peça publicitária da Natura presente na Marie Claire de abril de 2016 exemplifica muito bem essa questão. A peça não vincula um produto específico em seu texto, mas pela observação das imagens conclui-se que o produto em destaque seria sua linha de batons. O texto publicitário parece repetir a colocação de Sant'anna (2014) citada acima: "O trabalho da beleza tentaria aproximar aquilo que um rosto é de tudo aquilo que aparenta ser", sendo o texto publicitário o seguinte: "Beleza viva é tudo aquilo que você é, e tudo o que você quiser ser”. A frase em destaque também demonstra a apropriação que o mercado e a publicidade fizeram do ideário de liberdade e autonomia feminina.

Entretanto, a partir desse ideal, mais uma vez ocorre o encapsulamento das performances de feminilidades e de gênero, na medida em que as publicidades oferecem apenas um modelo aceitável e supostamente bem-sucedido de "ser mulher" no mundo moderno. Portanto, é imperioso levar em consideração que nesse caso a própria noção de liberdade é fictícia, uma vez que é produzida pela própria imprensa feminina e serve aos seus próprios interesses, deixando as motivações individuais das mulheres em segundo plano. A frase também é problemática no sentido de que a publicidade das revistas femininas geralmente trabalha o seu texto a partir de formas imperativas e ordenamentos de conduta, que por si só tolhem a liberdade de escolha, ou fabricam um sentimento falso de liberdade a partir de suas imposições. E por fim, o subtexto deixa claro a exaltação de uma "beleza natural" que pode ser acentuada pelo uso de cosméticos e não mais com o sentido corretivo ou de modificações de outrora, como pôde ser observado a partir das análises de A Cigarra.

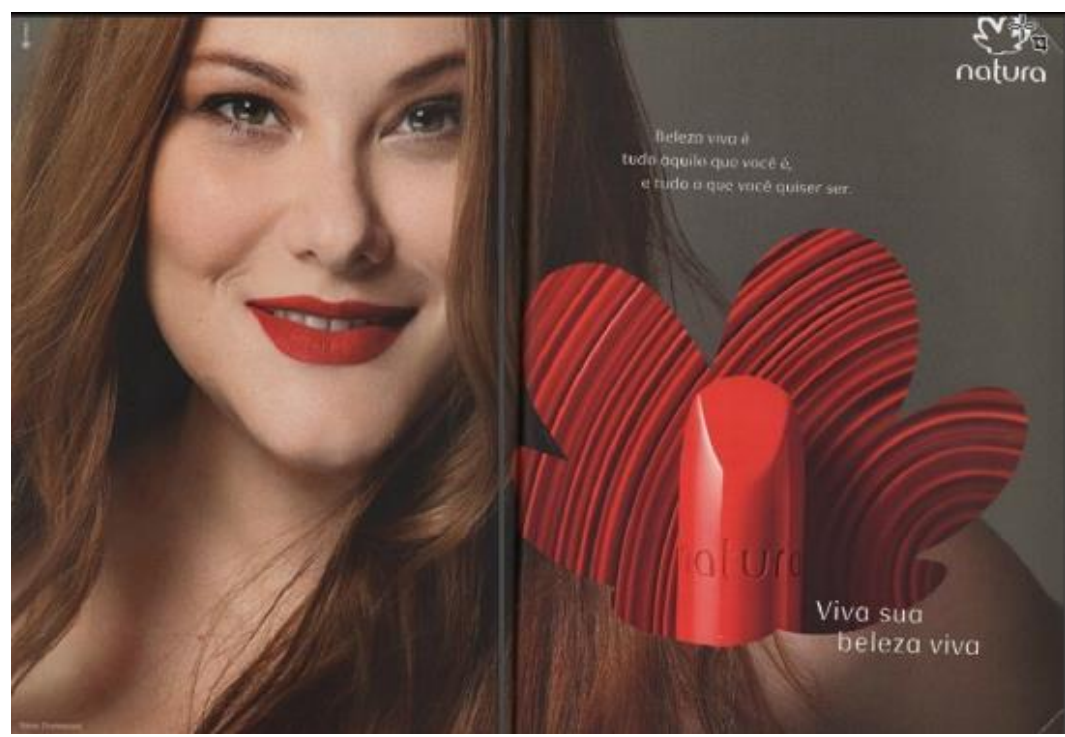

Figura 3. Batom Natura. Fonte: Marie Claire, № 301, Abril de 2016. 
Mais exemplos de peças publicitárias com um discurso pautado na exaltação da "beleza natural" foram encontrados durante minhas análises da revista Marie Claire, mesmo que de forma bem mais discreta. Um dos exemplos foi a propaganda da linha de protetores solares Cenoura \& Bronze encontrada na edição de janeiro de 2016 da revista. Apesar de ser um produto que não possui uma destinação clara de gênero - uma vez que a pele de todos está suscetível à radiação solar - a publicidade que ocupa uma página inteira da revista é ilustrada somente por imagens femininas. A questão da beleza natural se expressa pela chamada do canto inferior da página que traz os dizeres: "Cenoura \& Bronze. O protetor da sua beleza natural". Além da chamada, isso pode ser interpretado também a partir da identidade visual do anúncio publicitário, trazendo as mulheres que o ilustram em situações comuns do cotidiano, como andar de bicicleta à beira da praia tirando "selfies" sozinhas ou acompanhadas de amigas. Além da venda do protetor solar específico, a peça publicitária apresenta ainda modos de vida que são expressos por essas mesmas imagens de mulheres.

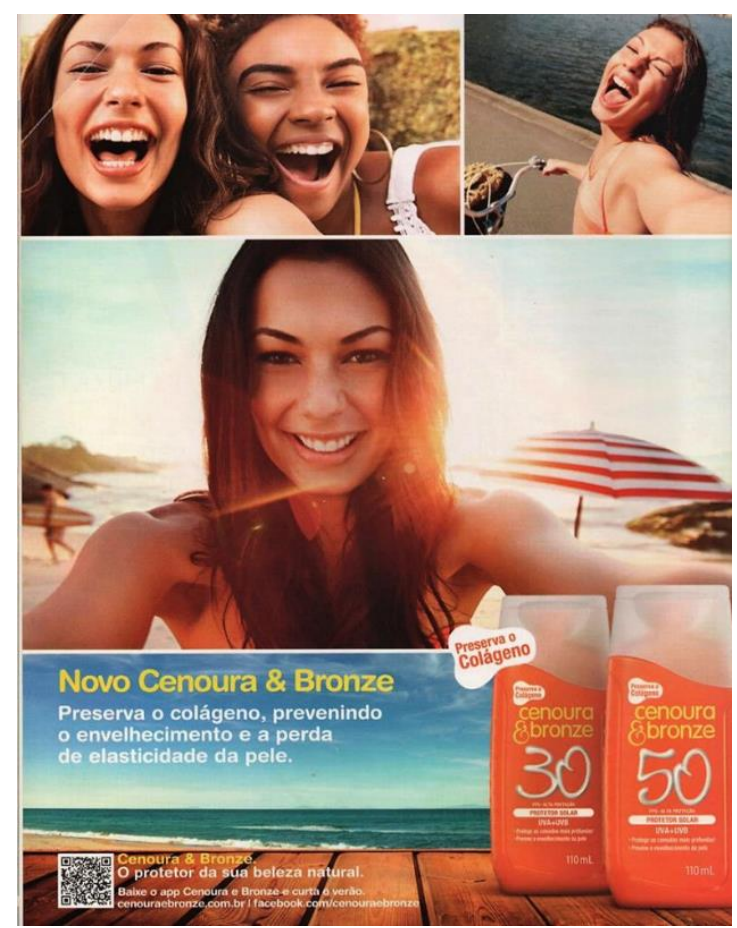

Figura 4. Cenoura \& Bronze. Fonte: Marie Claire, № 298, janeiro de 2016.

Além de tratar da questão da "beleza natural", a peça publicitária de Cenoura \& Bronze também trata da questão do envelhecimento, uma vez que promete a "prevenção do envelhecimento e perda de elasticidade da pele" a partir do uso do produto. Dessa forma, o envelhecimento e a perda de elasticidade são consequências associadas diretamente à exposição ao sol sem o uso de protetores solares. O que transparece aqui também é como a questão estética se sobressai frente a questões relacionadas a saúde, sendo ela pensada como forma mais eficaz de "vender" o produto pela mídia. Isso porque um discurso possível - e 
com consequências mais sérias e benéficas para o incentivo do uso de protetores solares e que poderia aqui ser usado - seria aquele pautado na questão da saúde pública, amparado no fato da comprovada eficácia do uso desse tipo de produto na prevenção do câncer de pele. Dessa forma, presume-se que a publicidade da imprensa feminina atual se sustenta mais por meio da valorização dos atributos estéticos. Surpreendentemente, mesmo que de forma exagerada, o discurso de prevenção de questões patológicas pelo uso de cosméticos aparecia de forma muito mais acentuada na publicidade presente na imprensa feminina da década de 1920 .

Diante das questões aqui apresentadas - como a da construção de uma beleza natural sempre em manutenção pelo uso de produtos cosméticos, e a prevenção do envelhecimento também pelo uso desses produtos - o que se torna explícito aqui é a existência de uma ideologia individualista moderna que se sustenta nessas peças publicitárias pela máxima de que o produto apresentado não atua por si só, cabendo ao leitor/ consumidor o cuidado com o próprio corpo, além do uso dos produtos.

No sentido de aliar essas duas lógicas, isto é, a da responsabilidade individual do cuidado com o próprio corpo e o envelhecimento, podemos utilizar o conceito de "reprivatização da velhice" cunhado com Guita Debert (1999) para arrematar os argumentos até aqui apresentados. Isso porque a relação entre as identidades da velhice e da "terceira idade" é discutida por Debert (1999) em inúmeros trabalhos, que interpreta o surgimento da "terceira idade" como um processo de "reprivatização da velhice". Por meio desta identidade, inaugurou-se a possibilidade de vivenciar o envelhecimento como uma etapa da vida prazerosa e gratificante, propícia para a realização de projetos e ambições. No entanto, tal vivência parece depender quase que exclusivamente do engajamento e da disciplina de cada indivíduo em fazer de sua velhice um momento de atividade e recriação, seguindo adequadamente as prescrições médicas e os modelos sociais, estéticos e afetivos que compõem o referido estilo de vida da terceira idade e que vêm sendo intensamente divulgados nos meios de comunicação.

Com o processo de reprivatização do envelhecimento, os sujeitos que não podem, não conseguem ou não querem criar para si uma velhice autônoma, ativa e prazerosa, identificada com os signos da terceira idade, são representados como dependentes, fracos ou ausentes, cujo estilo de vida é inadequado. No entanto, ainda que sejam depreciativas, tais imagens representariam uma alternativa de identificação para aqueles que não se enquadram no imaginário composto pela terceira idade, para os quais as imagens de saúde, atividade e vitalidade não seriam apropriadas.

Além das peças publicitárias de produtos para cuidados corporais como mostrado acima, a questão da valorização da "beleza natural" aparece na publicidade de maquiagens e produtos do gênero. Essa diferenciação de produtos para cuidados corporais e maquiagens torna-se aqui relevante, na medida em que, na publicidade veiculada na imprensa feminina da década de 1920, não havia a preocupação com a diferenciação entre as duas categorias, ou 
seja, não havia uma diferenciação clara entre propriedades cosméticas e medicinais entre os produtos.

\section{Publicidade e emoções na imprensa feminina}

A tônica das emoções na imprensa feminina pode ser apreendida principalmente a partir da análise do seu discurso publicitário. Muito comumente as peças publicitárias tematizam sobre emoções em seu conteúdo como estratégia de aproximação com seu público-alvo, as mulheres. A partir de minhas análises pude observar que tais discursos não aparecem de forma explícita, e são marcados principalmente pela sutileza na sua utilização. Podendo, por vezes, aparecer tanto no texto, quanto a partir das imagens vinculadas a essas peças publicitárias.

Na década de 1920, por exemplo, a partir do avanço da ciência higiênica, houve um ganho de espaço significativo para a propaganda de remédios para a saúde. Vários de seus anúncios, como os aqui analisados, mostravam figuras humanas atacadas por rostos contorcidos e olhares tristes, além de trazerem discursos sobre organismos lentos e obstruídos. Ainda não havia constrangimento em mostrar a sujeira, a doença e a feiura, nem pudores em pronunciar tais palavras. Dessa forma, no texto publicitário existiam longos discursos que tematizavam sobre o sofrimento associado a lentidão e sujeira dos organismos. A narrativa da lamúria em detrimento aos organismos congestionados funcionava como atrativo para a venda. (SANT'ANNA, 2011, p. 309). Ou seja, o artifício publicitário de convencimento girava em torno de produtos que evitavam aspectos negativos que poderiam se acometer ao corpo.

Diferentemente do que se observou na publicidade presente na imprensa feminina da década de 1920, questões como o sofrimento, tristeza e lamúrias não figuram mais como emoções a serem exploradas como chamariz pelo texto publicitário atual. Contrariamente a isso, as peças publicitárias atuais analisadas usam como chamariz emoções lidas positivamente, em especial, sentimentos como a felicidade. Ou seja, os discursos publicitários giravam em torno dos benefícios que o uso de tal produto traria ao indivíduo. Portanto, em vez de evitar o sofrimento, os produtos trariam benefícios que teriam como consequência a felicidade. Um exemplo disso pode ser apreendido se analisarmos mais demoradamente a peça publicitária de Cenoura \& Bronze exposta aqui anteriormente. Se concentrarmos nossas atenções nas fotografias da peça, o que é perceptível de imediato são os sorrisos das modelos, que indicam com clareza a ideia de felicidade que deseja ser transmitida pela peça publicitária.

Simplificando, na década de 1920 a publicidade dos produtos analisados era elaborada a partir de uma ideia pré-concebida de sofrimento inerente aos indivíduos, devido a seus organismos congestionados, que o produto remediaria. Na publicidade atual analisada, o indivíduo é tomado a partir de uma posição neutra, da qual é possível se alcançar a felicidade e emoções lidas como positivas a partir do uso dos produtos. 
Como abordado aqui anteriormente, uma das características marcantes da imprensa feminina é trazer explicitamente o seu direcionamento para as mulheres. Em efeito disso, a compreensão das emocões em sua publicidade é aquela arraigada nos papéis tradicionais de gênero: Lutz (1988) sobre a associação das emoções com os gêneros afirma:

O conceito de emoção existe em um sistema de relações de poder e desempenha um papel na manutenção deste [....] Identificando, primeiro, as emoções com a irracionalidade, a subjetividade, o caótico e outras características negativas, e em seguida etiquetando as mulheres como o gênero emocional, as crenças culturais reforçam a subordinação ideológica das mulheres (LUTZ, 1988, p.54)

Portanto, as mulheres são entendidas como mais emocionais, suscetíveis a se deixarem levar pelas emoções, como amor, tristeza, etc. Essa maior susceptibilidade emocional estaria associada às funções hormonais, enquanto os homens são percebidos como menos emotivos e mais racionais. Para compreender como as emoções são percebidas e trabalhadas pela imprensa feminina e sua publicidade, precisamos entender, antes de mais nada, qual a concepção ocidental moderna dominante em relação às emoções. A percepção das emoções pela imprensa feminina partiria de uma visão naturalista, isto é, de que as emoções são fenômenos comuns e naturais a todos os seres humanos. A capacidade de sentir emoções resultaria do equipamento biológico e psicológico inerente à espécie humana e seria, portanto, universal. Nesse modo de pensar, as emoções trariam poucas ou nenhuma marca das culturas nas quais as pessoas vivem (REZENDE; COELHO, 2010, p.20).

Esse modo de pensar as emoções é chamado por Lutz (1988) de "etnopsicologia ocidental moderna", conceito que se refere ao sistema de conhecimentos que define e explica o que é a pessoa - seus atributos, suas reações, seu modo de se relacionar com os outros -, algo que permite que ela monitore a si própria e aos outros, possibilitando assim alguma antecipação dos comportamentos. E possui dois pressupostos: a percepção de que as emoções estão ancoradas à dimensão psicobiológica do indivíduo e a noção consequente de que as emoções são constantes e universais. São essas noções que contribuem para a perspectiva de que as emoções são ancoradas no corpo. Um exemplo clássico usado como justificativa, e que se aplica ao caso da imprensa feminina, é a concepção dos hormônios como reguladores das emoções em relação ao gênero. Assim são frequentemente associados a uma maior emotividade feminina, tal como uma agressividade masculina, etc., e a partir disso suas fórmulas publicitárias são produzidas.

Considera-se também que as emoções possuem reações corporais. A tristeza gerando lágrimas, por exemplo. Assim, as emoções são fenômenos que acontecem no corpo, tanto em função de sua origem, quanto em função de suas manifestações. Porém, as noções sobre o funcionamento do corpo são diversas, assim como serão as maneiras de relacioná-las à emoção. Dessa forma, a maneira como explicamos as emoções tendo origem em processos 
corporais torna-se parte de uma visão culturalmente específica sobre o corpo, e não uma associação universalmente feita. Faz parte de nossa etnopsicologia, mas não de outras. Isso implica problematizar a qualidade da universalidade das emoções em função de uma unidade biológica e psíquica dos seres humanos (REZENDE; COELHO, 2010, p.30).

Mas isso não quer dizer que não se pode propor uma visão teórica sobre a relação do corpo e das emoções. Alguns autores, como Abu-Lughod, Lutz (1990) e Fajans (2006) trabalham essa questão a partir da noção de "emoções incorporadas", situadas no corpo, sem que isso implique afirmar que elas são naturais. Fajans (2006) afirma que, mesmo que as emoções possam surgir a partir de reações biológicas em um bebê, elas serão lembradas a partir de seu contexto de interação social; Abu-Lughod e Lutz (1990) ressaltam que o aprendizado de como e quando cada emoção deve ser expressada inclui também uma aquisição de um conjunto de técnicas corporais, gestos faciais e posturas. Portanto, mesmo que as emoções sejam situadas no corpo, têm com este uma relação que é permeada por significados historicamente e culturalmente construídos.

Portanto, a partir das análises é possível afirmar que a compreensão de "emoções" empregada pela imprensa feminina, tanto na década de 1920, quanto atualmente, coaduna com a noção de etnopsicologia ocidental moderna elaborada por Lutz (1988), ou seja, partindo de uma perspectiva naturalista. A diferenciação nesse caso se dá mais em relação a quais emoções são valorizadas em cada período histórico. Ou seja, na década de 1920 a cura do sofrimento é o chamariz das peças publicitárias. Atualmente o foco é na conquista da felicidade a partir da posse do produto das peças publicitárias.

\section{Considerações finais}

A partir dos aspectos aqui analisados, pode-se perceber o quanto o discurso publicitário da revista A Cigarra estimulava a produção de um "processo civilizador" (Elias, 1993). Norbert Elias (1993), ao tomar como objeto os variados tipos de comportamentos das sociedades de corte - a partir da análise de livros e manuais de comportamentos, de bons modos -, percebe que, de uma perspectiva histórica, isto é, de um ponto de vista a longo prazo, há um movimento de controle cada vez maior dos instintos humanos na sociedade ocidental. Um processo onde as estruturas emocionais incorporam controles instintuais cada vez maiores e se modificam de acordo com as transformações que acontecem na própria sociedade. Nesse sentido, a revista feminina no contexto da década de 1920 pode ser pensada como um desses manuais, uma vez que os discursos em seu interior incitam diversas condutas e normas para se adequar ao padrão aceito socialmente.

Esse processo civilizador se caracteriza como um movimento institucionalizado de afastamento cada vez maior da "naturalidade", ou uma caminhada ao controle dos impulsos. E que em muito pode ser ligada a períodos específicos na medida em que o autor demonstra como determinadas práticas comuns em um dado momento da história se transformavam em práticas inaceitáveis em outro. Dessa forma, o que é tido como aceito e apropriado socialmente são, na verdade, explicações que acontecem depois da escolha dos hábitos 
vigentes, ou melhor, são explicações localizadas historicamente que legitimam um dado hábito, que estabelece relações de dominação e de hierarquia.

Com as análises das peças publicitárias selecionadas de A Cigarra e Marie Claire, apesar de se pautarem em publicações distantes em quase um século entre elas, foi possível constatar a permanência de diversas características nos modos de se fazer imprensa feminina, e principalmente, em como esse tipo de imprensa colaborou para a produção de modelos de feminilidades pautados em padrões hegemônicos. Esses padrões são produzidos, pois de um modo geral, a mídia - enquanto elemento de centralidade e importância em nossa cultura - transformou-se numa força dominante de socialização, ajudando através de suas fórmulas e estereótipos a reforçar estes padrões. De acordo com Kellner (2001):

Suas imagens e celebridades substituem a família, a escola e a igreja como árbitros de gosto, valor e pensamento, produzindo novos modelos de identificação e imagens vibrantes de estilo, moda e comportamento, que se modificam e/ou se atualizam figurando novamente no meio midiático (KELLNER, 2001, p. 27).

Ainda em relação aos padrões e normas sociais, Judith Butler (2005) aponta como o de maior expressão aquele pautado na sexualidade, o que ela chama de "heteronorma". Em sua perspectiva, os sistemas normativos da sexualidade humana não afetam apenas os não-heterossexuais, mas dizem e estabelecem limites para aqueles/aquelas que se reconhecem como heterossexuais. O que está incluso ou não nas fronteiras do sexo é determinado por um processo de exclusão. A norma articula mecanismos disciplinares do corpo, servindo como elementos reguladores da população. E ela é sempre relacional visto que o "normal" depende do "anormal" para existir como tal. Este sistema heteronormativo estabelece condições sob as quais os corpos e comportamentos devem ser estruturados para tomar forma e serem legitimados. Essa legitimação encontra na imprensa feminina com suas fórmulas, um forte instrumento de legitimação e disseminação da norma.

Em relação ao "fazer" da imprensa feminina de uma forma geral, o que sobressai na comparação entre as revistas são os usos muito semelhantes da linguagem. Mais do que em relação à forma, o que mais chama a atenção é a intenção implícita por detrás de como a escrita é conduzida, que é praticamente idêntica. A linguagem utilizada pelas duas revistas em ambos os contextos visa conquistar a confiança da mulher, sugerindo subrepticiamente que a revista é uma ótima "conselheira", uma "melhor amiga", que consegue dar dicas sobre todos os assuntos, e possui as fórmulas para a resolução de todos os problemas do "mundo feminino"

Para conseguir isto, há toda uma forma específica de escrita utilizada nas duas publicações. Os textos são produzidos com uma linguagem coloquial, fazendo referência à leitora no uso da segunda pessoa, através dos pronomes de tratamento "você" e "vocês". Ainda no intuito de mostrar essa pessoalidade, a revista usa a linguagem fática ("viu? hein? 
hã?") a fim de manter o contato com quem está lendo os textos veiculados nela. Além disso, as sentenças empregadas sempre possuem um tom coloquial, que por detrás apresentam todo um ordenamento de conduta. $\mathrm{Na}$ imprensa feminina, além de informar, os textos dirigidos à mulher são verdadeira comunicação persuasiva, aconselhando-a a todo o momento sobre o que fazer, como fazer e, por fim, como ser. Presente em praticamente todo o conteúdo da revista, esses tipos de estratégias linguísticas aparecem de forma mais acentuada nas peças publicitárias.

Ainda sobre o uso da beleza e dos corpos femininos como ferramentas de controle pela imprensa feminina, a perspectiva teórica da autora feminista Naomi Wolf em sua obra "O Mito da Beleza" mostrou-se como um aparato teórico poderoso na produção de uma explicação viável sobre a permanência da centralidade desses aspectos durante os dois períodos históricos aqui analisados, fornecendo uma chave de arremate para os argumentos produzidos durante todo esse trabalho.

Wolf (2012) argumenta que, devido à luta das feministas nas últimas décadas, as mulheres conquistaram posições importantes na sociedade, tanto em termos legais como em termos profissionais. Entretanto, paralelamente a essa escalada de poder, a autora demonstra, a partir de dados estatísticos, que aumentaram os distúrbios ligados à alimentação, as cirurgias plásticas, a pornografia, etc. Fatores que colaboraram para a criação de necessidades artificialmente provocadas de corresponder a um modelo idealizado de mulher, em que a velhice e a obesidade, mais do que pecados, são motivos para a estigmatização

A partir disso, a autora formula o conceito de "mito da beleza", que segundo ela consiste em uma violenta reação contra o feminismo que emprega imagens da beleza feminina como uma arma política contra a evolução da mulher. O "mito da beleza" é a versão moderna de um reflexo social em vigor desde a Revolução Industrial. À medida que as mulheres se liberaram da mística feminina da domesticidade, o mito da beleza invadiu esse terreno perdido, expandindo-se enquanto tal mística definhava, para assumir sua tarefa de controle social. A questão da beleza se fortaleceu para assumir a função de coerção social que os mitos da maternidade, domesticidade, castidade e passividade não conseguem mais realizar (WOLF, 2012, p.79).

Portanto, "beleza" para Naomi Wolf, pode ser encarado como um sistema monetário semelhante ao padrão ouro. Como qualquer sistema, ele é determinado pela política e, na era moderna no mundo ocidental, consiste no último e melhor conjunto de crenças a manter certo domínio masculino. Ao atribuir valor às mulheres numa hierarquia vertical, de acordo com um padrão físico imposto culturalmente, ele expressa relações de poder segundo as quais as mulheres precisam competir de forma antinatural por recursos dos quais os homens se apropriaram (WOLF, 2012).

Por fim, o que persiste é que, no decorrer de todos esses anos, as mulheres conquistaram diretos legais e de reprodução, alcançaram a educação superior, entraram para o mundo dos negócios e das profissões liberais e derrubaram crenças antigas 
enquanto o seu papel social. Ainda assim, a imprensa feminina se pauta majoritariamente em padrões tradicionais já superados em vários aspectos. Pensar as emoções em relação aos gêneros é um desses aspectos que permaneceram. Pois, seja na publicidade da imprensa feminina da década de 1920, seja na atual, a perspectiva de que as mulheres são mais suscetíveis a fatores emocionais continua vigorando. Como já demonstrei em trabalhos anteriores (PEREIRA, 2017) ocorreram no decorrer dos anos modificações na imprensa feminina em relação ao seu conteúdo, porém mantiveram-se permanências em relação a sua forma. As emoções como chamariz publicitário permaneceram, porém os aspectos emocionais valorizados se modificaram. Na década de 1920 a valorização de um discurso pautado no sofrimento e sua resolução. Na publicidade atual a valorização de emoções percebidas como positivas, tal como a felicidade.

\section{Referências bibliográficas}

ABU-LUGHOD, Lila; LUTZ, Catherine. Introduction. In: Bedouin Stories. Berkeley. (Orgs.). Language and the politics of emotion. Cambridge: Cambridge University Press., 1990. p. 1-23.

A CIGARRA. São Paulo: O Cruzeiro, v. 1, n. 244, 1 jan. 1925. Quinzenal. Disponível em:<http://www.arquivoestado.sp.gov.br/site/acervo/repositorio_digital/jornais_revis tas>. Acesso em: 24 out. 2019

A CIGARRA. São Paulo: O Cruzeiro, v. 1, n. 245, 15 jan. 1925. Quinzenal. Disponível em:<http://www.arquivoestado.sp.gov.br/site/acervo/repositorio_digital/jornais_revis tas>. Acesso em: 24 out. 2019

ALMEIDA, Heloisa Buarque de. Melodrama comercial: reflexões sobre a feminilização da telenovela. Cadernos Pagu, n.19, p.171-194, 2002.

ANTONIO, Andrea Tochio de. Corpo e estética: um estudo antropológico da cirurgia plástica. (2008). Dissertação de Mestrado em Antropologia Social- Universidade Estadual de Campinas, São Paulo.

BELELI, Iara. Marcas da diferença na propaganda brasileira. 176f. (Tese de Doutorado em Ciências Sociais). Campinas: IFICH/UNICAMP, 2005.

. Corpo e identidade na propaganda. Revista Estudos Feministas, v. 15 n.1, p. 193215, 2007.

BUITONI, Dulcília Schoeder. Imprensa Feminina. São Paulo: Ática, 1986. (Série Princípios, 41).

Mulher de Papel: a representação da mulher pela imprensa feminina brasileira. 2. ed. São Paulo: Summus, 2009.

BUTLER, Judith. Cuerpos que importan: sobre los limites materiales y discursivos del sexo. Buenos Aires: Paidós, 2005.

ELIAS, Norbert. O processo civilizador. Vol. I: uma História dos Costumes. 2 ed. Rio de Janeiro: Zahar, 2011, p. 264. 
FAJANS, Jane. Autonomy and relatedness: emotions and their tensions between individuality and sociality. Critique of Antropology, v.26, n.1, p. 108-119, 2006.

HEILBORN, Maria Luiza e SORJ, Bila. "Estudos de Gênero no Brasil”. In: Miceli, Sergio (org). O que ler nas ciências sociais brasileira (1970-1995). São Paulo: Editora Sumaré: ANPOCS; Brasília, DF: CAPES, 1999.

KELLNER, Douglas. A cultura da mídia: estudos culturais: identidade e política entre o moderno e o pós-moderno. Bauru: Edusc, 2001.

LUTZ, Catherine. Unnatural Emotions - everyday sentiments on a Micronesian attol and their challenge to Western theory. Chicago: University of Chicago Press. 1988

MARIE CLAIRE. Brasil: Editora Globo, v. 298, jan. 2016. Mensal.

MARIE CLAIRE. Brasil: Editora Globo, v. 299, fev. 2016. Mensal.

MARIE CLAIRE. Brasil: Editora Globo, v. 300, mar. 2016. Mensal.

MARIE CLAIRE. Brasil: Editora Globo, v. 301, abr. 2016. Mensal.

MARIE CLAIRE. Brasil: Editora Globo, v. 302, maio 2016. Mensal.

MARIE CLAIRE. Brasil: Editora Globo, v. 303, jun. 2016. Mensal

MORIN, Edgar. Cultura de massas no século XX: vol. 1 -Neurose. 10. ed. São Paulo: Forense Universitária, 2011.

ORTNER, Sherry B. Está a mulher para o homem assim como a natureza para a cultura? In: ROSALDO, Michelle; LAMPHERE, Loise. (orgs). A mulher, a cultura e a sociedade. Rio de Janeiro: Paz e Terra, 1979

PEREIRA, Charles Antônio. Entre "seios aformoseados" e "viva sua beleza": feminilidades em contraste na publicidade da imprensa feminina. 95f. (Dissertação de Mestrado em Ciências Sociais). Juiz de Fora: PPGCS/UFJF, 2017.

PERROT, Michelle. Minha história das mulheres. 1. ed. São Paulo: Contexto, 2008.

PRIORE, Mary del; AMANTINO, Mácia (Org.). História do Corpo no Brasil. São Paulo: Unesp, 2011.

REZENDE, Claudia Barcellos; COELHO, Maria Claudia. 2010. Antropologia das Emoções. Rio de Janeiro: Editora FGV.

SANT'ANNA, Denise Bernuzzi de. História da beleza no Brasil. São Paulo: Contexto, 2014. $205 \mathrm{p}$.

. "Cuidados de Sí e embelezamento feminino: fragmentos para uma história do corpo no Brasil. In. (Org.). Políticas do corpo: elementos para uma história das práticas corporais. São Paulo: Estação Liberdade, 1995.

SANT'ANNA, Denise Bernuzzi. Higiene e higienismo entre o Império e a República. In: PRIORE, Mary del; AMANTINO, Marcia (Org.). História do Corpo no Brasil. 2. ed. São Paulo: Unesp, 2011.

SANTOS, Chrislene Carvalho dos. História e Propaganda: análise de corpos femininos em imagens publicitárias na década de 20. Revista História Hoje, v. 3, n. 9. 2006.

SIQUEIRA, Denise da Costa Oliveira (Org.). O Corpo Representado: mídia, arte e produção de sentidos. Rio de Janeiro: Eduerj, 2014. 252 p. 
SULLEROT, Evelyne. La presse féminine. Paris: Armand-Colin, 1963.

WOLF, Naomi. O mito da beleza: como as imagens de beleza são usadas contra as mulheres. São Paulo: Rosa dos Tempos, 2012.

\section{Charles Antônio Pereira}

É mestre em Ciências Sociais pela Universidade Federal de Juiz de Fora, com graduação em Ciências Sociais e Interdisciplinar em Ciências Humanas, pela mesma instituição.

Recebido em 14/11/2019

Aceito para publicação em 27/12/2019 